JMI Vol. 40 No. 1 Juni 2018

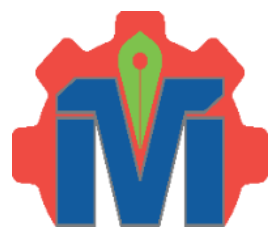

METAL INDONESIA

\title{
PENGARUH TEMPERATUR DAN WAKTU TAHAN PROSES PERLAKUAN PANAS TEMPER TERHADAP STRUKTUR MIKRO DAN KEKERASAN PERMUKAAN RIM RODA KERETA API PROTOTIPE HASIL PENGERASAN INDUKSI
}

\section{EFFECT OF TEMPERING TEMPERATURE AND HOLDING TIME ON MICROSTRUCTURE AND SURFACE HARDNESS OF INDUCTION HARDENED TRAIN WHEEL PROTOTYPE}

\author{
Martin Doloksaribu ${ }^{1}$, Sri Bimo Pratomo ${ }^{2}$, Rizal Hanifi ${ }^{3}$ dan Muhamad Yusup Malik Arifin ${ }^{3}$ \\ ${ }^{1}$ Balai Besar Logam dan Mesin, Jalan Sangkuriang No. 12 Bandung 40135, Jawa Barat, Indonesia, \\ email : mrtn.ds@gmail.com \\ ${ }^{2}$ Balai Besar Logam dan Mesin, Jalan Sangkuriang Nomor 12 Bandung 40135, Jawa Barat, Indonesia \\ ${ }^{3}$ Fakultas Teknik Universitas Singaperbangsa Karawang, Jawa Barat, Indonesia
}

\begin{abstract}
Abstrak
Prototipe roda kereta api telah dibuat dengan metode pengecoran gravitasi namun kekerasan permukaan belum memenuhi standar. Penelitian ini dilakukan untuk meningkatkan kekerasan prototipe roda kereta api agar mencapai nilai kekerasan sesuai standar dengan metode perlakukan panas. Prototipe roda kereta api diberikan perlakuan panas induction hardening (pengerasan induksi) dan didinginkan dengan media air. Prototipe roda kereta api hasil pengerasan induksi diberikan perlakuan panas temper untuk meningkatkan keuletan dan ketangguhan dengan menurunkan kekerasan. Perlakuan panas temper dilakukan pada termperatur $500^{\circ} \mathrm{C}, 600^{\circ} \mathrm{C}$ dan $700^{\circ} \mathrm{C}$ dengan waktu tahan selama 1 dan 3 jam. Uji komposisi kimia, uji keras dan pengamatan struktur mikro dilakukan terhadap spesimen prototipe roda kereta api dan roda kereta api impor sebagai pembanding. Hasil uji kekerasan pada spsimen pengerasan induksi pada $900^{\circ} \mathrm{C}$ adalah $381 \mathrm{HB}$ (41 HRC). Hasil uji kekerasan pada spesimen perlakuan panas temper adalah 311, 258 dan $243 \mathrm{HB}$ untuk temperatur temper $500^{\circ} \mathrm{C}, 600^{\circ} \mathrm{C}$ dan $700^{\circ} \mathrm{C}$ dengan waktu tahan selama 1 jam. Sedangkan hasil uji kekerasan pada spesimen perlakuan panas temper pada temperatur $500^{\circ} \mathrm{C}, 600^{\circ} \mathrm{C}$ dan $700^{\circ} \mathrm{C}$ dengan waktu tahan 3 jam adalah 271, 253 dan 237 HB. Nilai tersebut lebih besar dibandingkan nilai kekerasan roda kereta api impor yaitu $237 \mathrm{HB}$ (21 HRC). Struktur mikro menunjukkan peningkatan fasa ferit dengan meningkatkanya temperatur temper dan waktu tahan. Kekerasan paling besar adalah $311 \mathrm{HB}$ (33 $\mathrm{HRC}$ ) pada temperatur temper $500^{\circ} \mathrm{C}$ dengan waktu tahan selama 1 jam.
\end{abstract}

Kata kunci : ferit, kekerasan, perlakuan panas temper, roda kereta api

\begin{abstract}
The train wheel prototype has been made by gravity casting method but surface hardness was under the standard. The purpose of this research was to improve the surface hardness of the train wheel prototype by heat treatment. The train wheel prototype was given induction hardening then cooled by water. The toughness of induction hardened train wheel prototype were improved by tempering. Tempering will reduce hardness but will improve toughness. Tempering temperature was set at $500^{\circ} \mathrm{C}$, $600^{\circ} \mathrm{C}$ and $700^{\circ} \mathrm{C}$ with 1 and 3 hours of holding time. Chemical composition tests, hardness tests and microstructure observations were carried out on specimens of prototype and specimen of imported train wheel. The hardness of induction hardened train wheel prototype at $900^{\circ} \mathrm{C}$ was $381 \mathrm{HB}(41$ $H R C)$. The hardness of induction hardened train wheel were 311,258 and $243 \mathrm{HB}$ for $500^{\circ} \mathrm{C}, 600^{\circ} \mathrm{C}$ and $700^{\circ} \mathrm{C}$ with 1 hour of holding time and 271,253 and $237 \mathrm{HB}$ for $500^{\circ} \mathrm{C}, 600^{\circ} \mathrm{C}$ and $700^{\circ} \mathrm{C}$ with 3 hours of holding time. The hardness of imported train wheel was 237 HB (21 HRC). The microstructure of train wheel prototype shows bainite phase with more ferrite phase as increasing of
\end{abstract}


tempering temperatures and holding time. The highest hardness was $311 \mathrm{HB}(33 \mathrm{HRC})$ at $500^{\circ} \mathrm{C}$ and 1 hour of holding time.

Keywords : ferrite, hardness, tempering, train wheel

\section{PENDAHULUAN}

Beberapa komponen pada satu unit kereta api merupakan komponen yang cepat habis. Namun belum banyak kompoen kereta api yang dapat diproduksi di dalam negeri. Kementerian perindustrian mencatat bahwa tingkat komponen dalam negeri (TKDN) dalam satu unit kereta di Indonesia masih kurang dari 50\% (Aditiasari 2015). Sebagian besar komponen kereta api masih mengandalkan barang impor.

Industri perkeretaapian Indonesia memiliki potensi untuk menguasai pasar manufaktur perkeretaapian. Pemerintah mendorong industri dalam negeri agar dapat meningkatkan kapasitasnya agar mampu memenuhi kebutuhan dalam negeri (Djumena 2018). Kemampuan manufaktur terhadap komponen-komponen impor terutama pada komponen dengan tingkat penggantian yang tinggi perlu terus dikembangkan.

Roda kereta api merupakan salah satu komponen dengan tingkat penggantian yang tinggi. Roda kereta api yang telah mengalami pengurangan ketebalan sebesar $1 \mathrm{~cm}$ akan diganti dengan roda yang baru. Penambahan ketebalan terhadap roda kereta api yang telah tidak layak pakai dapat dilakukan namun sifat mekanik permukaan tidak memenuhi syarat.

Spesifikasi roda kereta api mensyaratkan kekerasan pada bagian body sebesar $293 \mathrm{HB}$ dan bagian telapak sebesar 320 341 HB. Hasil pengujian kekerasan roda kereta api impor belum memenuhi Spesifikasi Teknik Roda Solid Kereta dan Gerbong Golongan CC PT KAI (PTKAI 2009).

Pratomo (2013) telah membuat roda kereta api dengan metode pengecoran gravitasi dengan menggunakan cetakan pasir. Proses pengecoran (casting) memperhatikan komposisi Mn sesuai kisaran komposisi standar karena Mn mempengaruhi kekuatan struktur roda kereta (Pratomo 2013). Bagian body roda kereta api produk cor sudah sesuai JIS E5402:1998 namun kekerasan pada bagian telapak belum mencapai standar.

Kekerasan permukaan telapak roda kereta api merupakan karateristik penting karena pada area tersebut akan bersentuhan langsung dengan lintasan rel. Seiring lamanya penggunaan roda kereta api maka bagian telapak tersebut akan mengalami keausan sehingga ketebalan permukaan akan berkurang.

Peningkatan kekerasan telah dilakukan dengan penambahan unsur paduan dan perlakuan panas (Pratomo et al. 2016). Penambahan unsur mangan $(\mathrm{Mn})$, krom $(\mathrm{Cr})$, molibden $(\mathrm{Mo})$, nikel $(\mathrm{Ni})$, dan tembaga $(\mathrm{Cu})$ disertai perlakuan panas normalisasi menghasilkan kekerasan lebih tinggi daripada roda kereta api impor. Penambahan $\mathrm{Cr}$ mampu meningkatkan kekerasan. Jumlah penambahan unsur paduan perlu dibatasi karena penambahan unsur paduan tertentu yang terlalu banyak dapat menurunkan sifat mekanik (Jiang et al. 2016).

Perbedaan metode perlakuan panas mampu memberikan kekerasan yang berbeda. Perlakuan panas normalisasi dengan pendinginan udara menghasilkan kekerasan roda kereta api sebesar 25 31 HRC (250 290 HB). Sedangkan normalisasi dengan pendinginan kipas menghasilkan kekerasan yaitu 31 36 (290 331 HB). Roda kereta api dengan kekerasan yang terlalu tinggi memiliki ketangguhan yang rendah. Ketangguhan yang rendah menyebabkan crack pada saat penggunaan (Doloksaribu and Afrilinda 2016).

Penelitian ini bertujuan untuk meningkatkan kekerasan telapak prototipe roda kereta api yang telah diberikan pengerasan induksi dengan perlakuan panas temper. Variasi perlakuan panas temper yang optimal diteliti pada penelitian ini sehingga kekerasan pada telapak roda kereta masih memenuhi standar PT. KAI namun memiliki ketangguhan yang lebih baik.

\section{METODOLOGI}

Alur penelitian dapat dilihat pada Gambar 1. Prototipe roda kereta api diberikan perlakuan panas pengerasan induksi pada temperatur $900^{\circ} \mathrm{C}$ dan didinginkan dengan media pendingin air. Pengerasan induksi diberikan untuk meningkatkan kekerasan pada permukaan. Spesimen penelitian dipotong dari bagian telapak (rim) prototipe roda kereta api yang telah diberikan perlakukan panas pengerasan induksi tersebut. Pengecekan 
komposisi kimia, uji keras dan pengamatan struktur mikro dilakukan pada spesimen tersebut.

Kemudian spesimen tersebut diberikan perlakuan panas temper pada temperatur 500, $600,700^{\circ} \mathrm{C}$ dengan waktu tahan 1 dan 3 jam. Pengujian keras dan pengamatan struktur mikro juga dilakukan pada spesimen roda kereta impor sebagai pembanding.

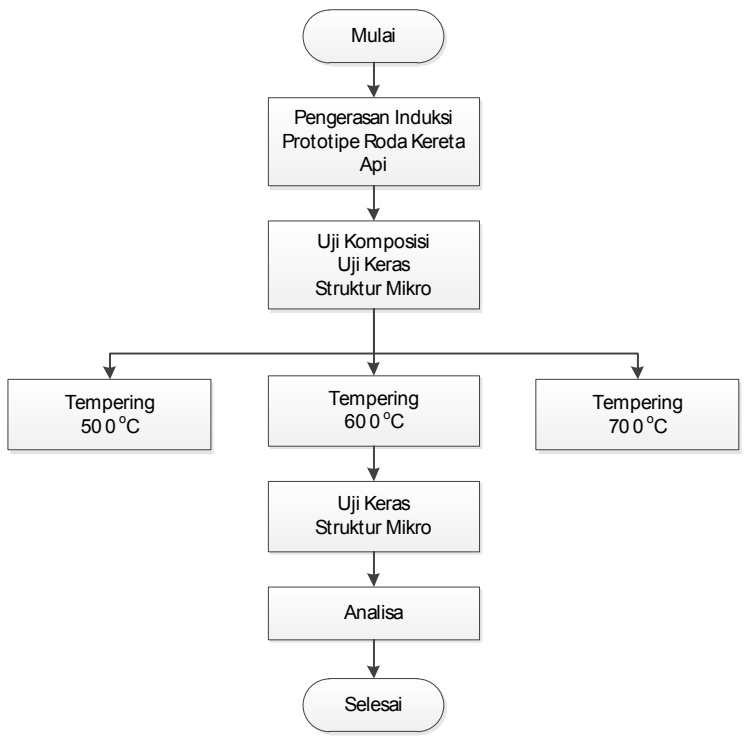

Gambar 1. Alur penelitian

Mesin/peralatan yang digunakan pada penelitin ini adalah mesin potong merk LECO, spektrometer PMI MASTER PRO, tungku perlakuan panas untuk proses perlakuan panas temper merk DEGUSA, mesin uji kekerasan Rockwell merk AFRI SYSTEM, mesin grinding dan polishing merk TAIWAN NAKAZAWA dan mikroskop optik merk NIKON. Bahan-bahan yang digunakan pada pengamatan struktur mikro yaitu kain beludru, ampelas, alumina dan nital $2 \%$.

Kegiatan penelitian dilakukan pada November s/d Desember 2014 di Balai Besar Logam dan Mesin.

\section{HASIL DAN PEMBAHASAN}

Prototipe roda kereta api dapat ditunjukkan pada Gambar 2. Kotak merah menandakan area potong spesimen.

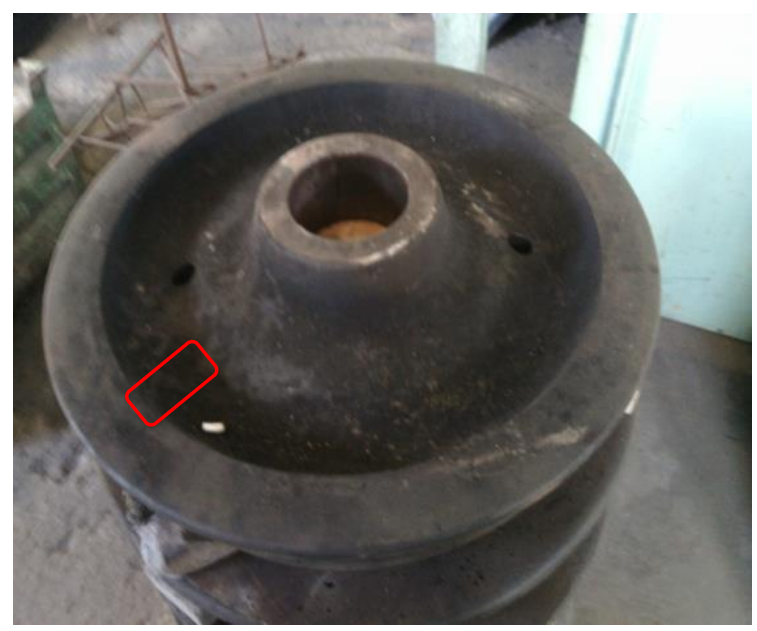

Gambar 2. Produk cor prototipe roda kereta api

Spesimen untuk pengujian dan perlakuan panas temper dipotong dari produk tersebut. (Gambar $3)$.

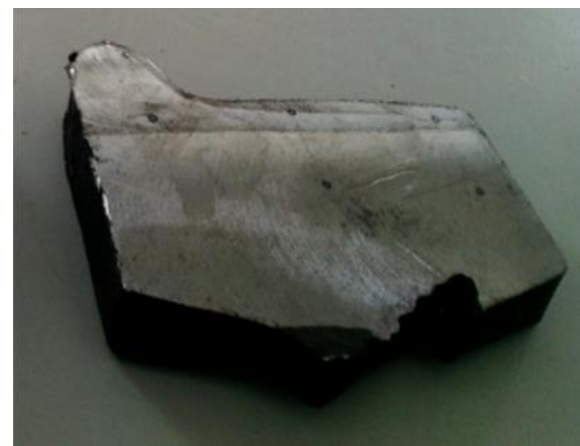

Gambar 3. Spesimen untuk pengujian dan perlakuan panas temper

Uji komposisi kimia dilakukan pada spesimen roda kereta api prototipe dan impor (Tabel 1). Hasil komposisi dibandingkan dengan standar komposisi roda kereta api berdasarkan golongan $\mathrm{CC}$ yang dikeluarkan oleh PT KAI.

Tabel 1. Komposisi kimia Roda KA Prototipe dan Impor

\begin{tabular}{|l|r|r|r|r|r|}
\hline \multirow{2}{*}{$\begin{array}{c}\text { Roda Kereta } \\
\text { Api }\end{array}$} & \multicolumn{5}{|c|}{ Unsur (\%wt) } \\
\cline { 2 - 6 } & \multicolumn{1}{c|}{$\mathrm{C}$} & \multicolumn{1}{c|}{$\mathrm{Mn}$} & \multicolumn{1}{c|}{$\mathrm{Si}$} & \multicolumn{1}{c|}{$\mathrm{P}$} & \multicolumn{1}{c|}{$\mathrm{S}$} \\
\hline Prototipe & 0.639 & 0.941 & 0.380 & 0.019 & 0.013 \\
\hline Impor & 0.518 & 0.759 & 0.317 & 0.012 & 0.008 \\
\hline $\begin{array}{l}\text { Standar PT } \\
\text { KAI }\end{array}$ & $0.60 \sim 0.75$ & $0.50 \sim 0.90$ & $0.15 \sim 0.35$ & Max 0.05 & Max 0.05 \\
\hline
\end{tabular}

Kandungan karbon (C) pada roda kereta api prototipe lebih besar daripada roda kereta api impor akan tetapi kandungan $\mathrm{C}$ pada roda kereta api prototipe masuk dalam kisaran standar. Secara umum kandungan C 
berpengaruh terhadap kekuatan tarik, keuletan dan sifat mampu las pada roda kereta tersebut. Semakin besar kandungan $\mathrm{C}$ maka kekerasan makin tinggi.

Kandungan unsur mangan (Mn) dan silikon $(\mathrm{Si})$ pada roda kereta prototipe sedikit di atas nilai standar. Baja dengan Mn tinggi memberikan sifat tahan aus yang baik (Lu et al. 2015). Sedangkan dengan bertambahnya Si dalam jumlah sedikit dapat meningkatkan kemampuan untuk dikeraskan (hardenability) dan dalam jumlah banyak akan menurunkan keuletan.

Kekerasan spesimen roda kereta api prototipe dan impor dapat dilihat pada Tabel 2 dan Gambar 4. Kekerasan spesimen prototipe roda kereta api hasil pengerasan induksi di atas kekerasan roda kereta api impor maupun standar PT KAI.

Tabel 2. Nilai kekerasan spesimen

\begin{tabular}{|l|c|c|}
\hline \multirow{2}{*}{\multicolumn{1}{|c|}{ Spesimen }} & \multicolumn{2}{c|}{ Kekerasan } \\
\cline { 2 - 3 } & HRC & HB \\
\hline $\begin{array}{l}\text { Prototipe Sebelum } \\
\text { Pengerasan Induksi }\end{array}$ & 18 & 172.5 \\
\hline $\begin{array}{l}\text { Prototipe Setelah } \\
\text { Pengerasan Induksi }\end{array}$ & 41.08 & 381 \\
\hline Impor & 21.78 & 237 \\
\hline Standar PT KAI & & $320 \sim 341$ \\
\hline
\end{tabular}

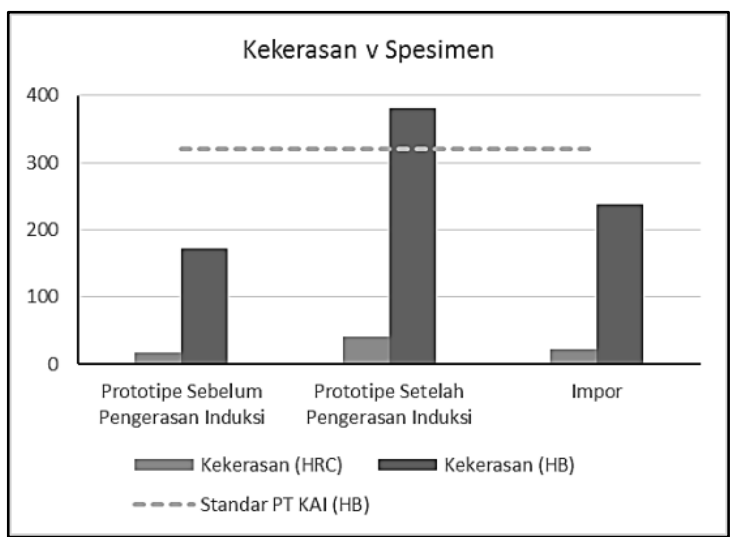

Gambar 4. Grafik kekerasan terhadap spesimen

Pengerasan induksi (induction hardening) dapat meningkatkan kekerasan permukaan prototipe roda kereta api dari 18 HRC (hasil cor sebelum pengerasan induksi) menjadi 41.08 HRC. Peningkatan kekerasan permukaan disebabkan oleh terbentuknya martensit dan bainit akibat dari proses pengerasan induksi. Berbeda dengan roda kereta api impor, struktur mikro yang terbentuk adalah ferit dan perlit yang memiliki sifat lunak. Spesimen yang telah dilakukan pengerasan induksi tersebut diberikan perlakuan panas temper. Perlakuan panas temper dilakukan untuk mengurangi tegangan sisa dan meningkatkan ketangguhan yaitu kombinasi kekerasan dan kekuatan. Temperatur temper yang diberikan adalah $500^{\circ} \mathrm{C}, 600^{\circ} \mathrm{C}$ dan $700^{\circ} \mathrm{C}$ dengan masing-masing waktu tahan (holding time) selama 1 jam. Hasil uji keras dapat dilihat pada Tabel 3 dan Gambar 5.

Tabel 3. Kekerasan terhadap temperatur temper dengan waktu tahan selama 1 jam

\begin{tabular}{|c|c|c|c|}
\hline $\begin{array}{c}\text { Temperatur } \\
{ }^{\circ} \mathrm{C}\end{array}$ & $\begin{array}{c}\text { Waktu Tahan } \\
\text { Jam }\end{array}$ & \multicolumn{2}{|c|}{ Kekerasan } \\
\cline { 3 - 4 } & 1 & HRC & HB \\
\hline 500 & 1 & 26 & 311 \\
600 & 1 & 23 & 243 \\
700 & & \\
\hline
\end{tabular}

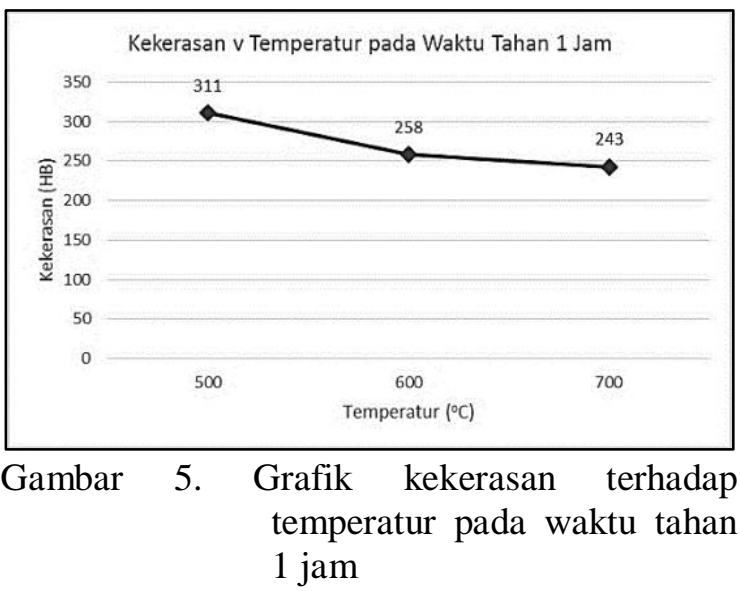

Pada Gambar 5 di atas dapat dilihat bahwa semakin meningkat termperatur temper maka kekerasan akan menurun. Penurunan kekerasan sangat signifikan pada kenaikan temperatur temper dari $500 \mathrm{ke} 600^{\circ} \mathrm{C}$ yaitu 53 HB. Kemudian kekerasan berkurang sebesar 15 $\mathrm{HB}$ dari temperatur $600^{\circ} \mathrm{C}$ ke $700^{\circ} \mathrm{C}$. Kekerasan terbesar terjadi pada temperatur temper sebesar $500^{\circ} \mathrm{C}$ yaitu $311 \mathrm{HB}$. Perlakuan panas temper (tempering) menyebabkan kekerasan turun namun dapat meningkatkan ketangguhan (toughness) (Parzych 2017).

Perlakuan panas temper dilakukan untuk waktu tahan selama 3 jam. Hasil kekerasan dapat dilihat pada Tabel 4 dan Gambar 6. 
Tabel 4. Kekerasan terhadap temperatur temper dengan holding time selama 3 jam

\begin{tabular}{|c|c|c|c|}
\hline $\begin{array}{c}\text { Temperatur } \\
{ }^{\circ} \mathrm{C}\end{array}$ & $\begin{array}{c}\text { Waktu Tahan } \\
\text { Jam }\end{array}$ & \multicolumn{2}{|c|}{ Kekerasan } \\
\cline { 3 - 4 } & 3 & HRC & HB \\
\hline 500 & 3 & 25 & 271 \\
600 & 3 & 22 & 253 \\
700 & 3 & 237 \\
\hline
\end{tabular}

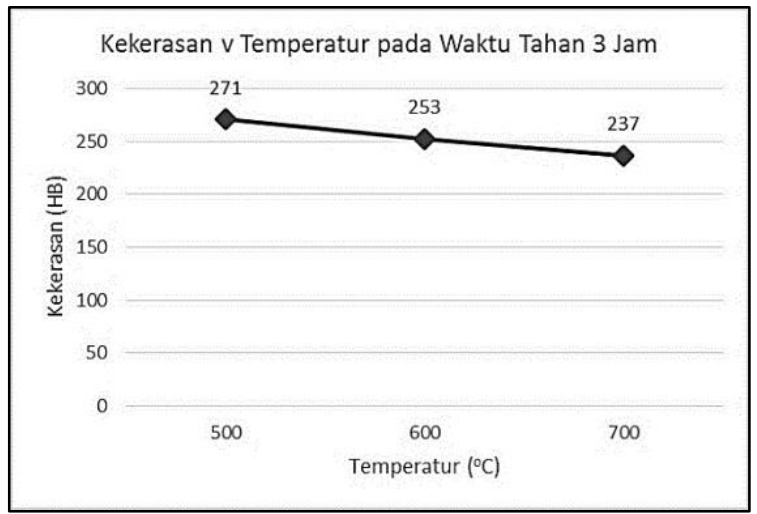

Gambar 6. Grafik kekerasan terhadap temperatur pada waktu tahan 3 jam

Pada Gambar 6 dapat dilihat bahwa semakin meningkat temperatur temper maka kekerasan menurun. Penurunan kekerasan relatif stabil dibandingkan pada waktu tahan selama 1 jam. Kekerasan berkurang sebesar 18 $\mathrm{HB}$ dari temperatur $500^{\circ} \mathrm{C}$ ke $600^{\circ} \mathrm{C}$. Kemudian berkurang sebesar $16 \mathrm{HB}$ dari $600^{\circ} \mathrm{C}$ ke $700^{\circ} \mathrm{C}$. Kekerasan terbesar terjadi pada temperatur temper $500^{\circ} \mathrm{C}$ sebesar 271 HB. Kekerasan tersebut lebih kecil pada nilai kekerasan dengan temperatur temper yang sama namun dengan waktu tahan yang lebih singkat. Semakin lama waktu tahan menyebabkan kekerasan menurun.

Semakin meningkat temperatur temper maka kekerasan akan menurun. Hal ini terjadi karena semakin tinggi temperatur temper maka akan semakin banyak ferit yang terbentuk. Jumlah ferit yang semakin banyak akan menurunkan kekerasan.

Peningkatan waktu tahan memberi dampak pada penurunan kekerasan. Kekerasan pada waktu tahan 1 jam lebih besar daripada kekerasan pada waktu tahan 3 jam. Hal tersebut dapat dilihat pada Tabel 5 dan Gambar 7.
Tabel 5. Perbandingan kekerasan pada variasi temperatur dan waktu tahan

\begin{tabular}{|c|c|c|c|}
\hline \multirow{2}{*}{$\begin{array}{c}\text { Waktu Tahan } \\
\text { Jam }\end{array}$} & \multicolumn{3}{|c|}{ Kekerasan (HRC) } \\
\cline { 2 - 4 } & $500^{\circ} \mathrm{C}$ & $600^{\circ} \mathrm{C}$ & $700^{\circ} \mathrm{C}$ \\
\hline 1 & 33 & 26 & 23 \\
3 & 28 & 25 & 22 \\
\hline
\end{tabular}

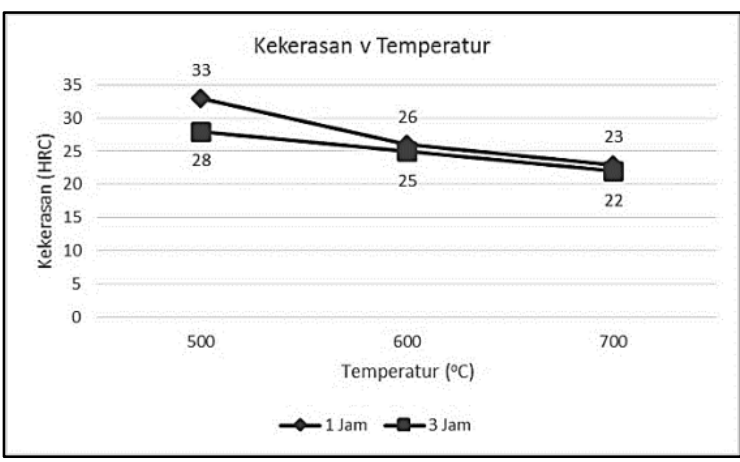

Gambar 7. Kekerasan terhadap temperatur pada waktu tahan 1 jam dan 3 jam

Struktur mikro permukaan rim roda kereta impor dapat dilihat pada Gambar 8 di bawah ini. Struktur pada roda kereta api impor adalah ferit dan perlit. Fasa ferit terlihat berwarna terang. Fasa ferit mempunyai sifat lunak. Fasa perlit terlihat berwarna gelap merupakan lapisan ferit dan sementit. Fasa perlit mempunyai sifat mampu mesin yang baik.

Kekuatan dan kekasaran struktur ferit dan perlit ditentukan oleh beberapa faktor salah satunya adalah temperatur austenisasi. Temperatur austenisasi yang semakin tinggi di atas garis transformasi besi- $\alpha$ dan besi- $\gamma$ menjadi austenit (besi- $\gamma+\mathrm{Fe}_{3} \mathrm{C}$ ) akan menghasilkan butir austenit yang semakin besar. Pada saat pendinginan lambat, semakin besar butir austenit maka akan menghasilkan ferit dan perlit yang semakin kasar. Selain itu, kekuatan dan kekerasan struktur perlit dipengaruhi oleh jarak antar lapisan tipis (lamellar spacing) sementit. Semakin kecil lamellar spacing maka jumlah sementit semakin banyak sehingga semakin keras struktur perlit tersebut. 


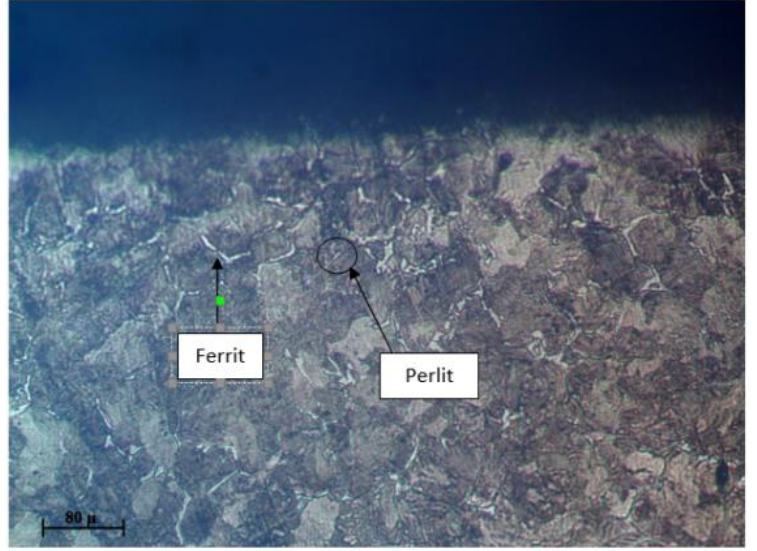

Gambar 8. Struktur mikro permukaan rim roda kereta impor (perbesaran 200X; daerah pinggir)

Struktur mikro permukaan prototipe roda kereta yang telah melalui proses pengerasan induksi pada temperatur $900^{\circ} \mathrm{C}$ dengan media pendinginan air dapat dilihat pada Gambar 9. Pada area struktur mikro yang tampak pada Gambar 9 terdapat struktur bainit pada bagian permukaan (Pratomo, Hafid, and Afrilinda 2013). Struktur mikro yang terbentuk mempengaruhi nilai kekerasan. Selain itu, nilai kekerasan juga dipengaruhi oleh kehomogenan struktur (Doloksaribu and Afrilinda 2014).

Penurunan temperatur dengan media air dari temperatur pengerasan induksi $900^{\circ} \mathrm{C}$ ke temperatur di bawah $723^{\circ} \mathrm{C}$ menyebabkan pembentukan fasa martensit dan juga fasa bainit. Struktur bainit dapat terjadi akibat kecepatan waktu pendinginan menengah (moderat). Kecepatan waktu pendinginan tersebut tidak terlalu lambat sehingga tidak terjadi pembentukan perlit dan tidak terlalu cepat sehingga austenit tidak seluruhnya bertransformasi menjadi struktur martensit.

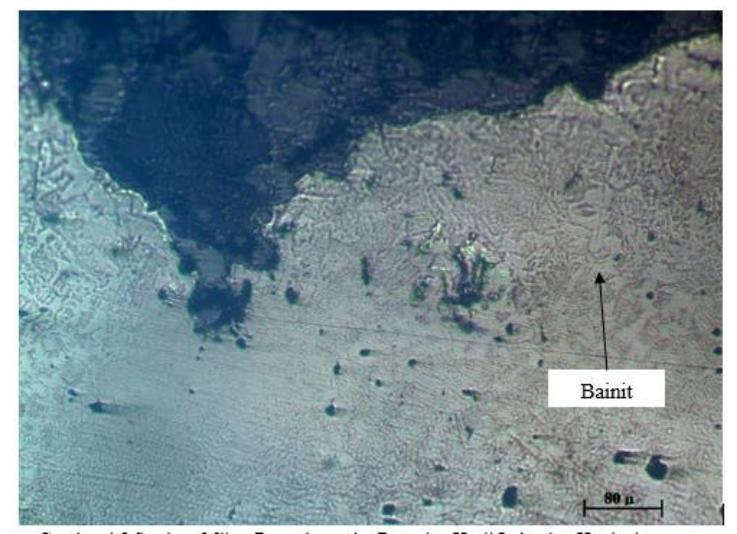

Gambar 9. Struktur mikro permukaan rim prototipe roda kereta api hasil pengerasan induksi $900^{\circ} \mathrm{C}$ - (perbesaran

200X; daerah pinggir)

Struktur mikro prototipe roda kereta api hasil perlakukan panas temper pada temperature 500,600 dan $700^{\circ} \mathrm{C}$ pada waktu tahan selama 1 jam dapat dilihat pada Gambar 10. Grafik nilai kekerasan terhadap temperatur (Gambar 7) menunjukkan semakin besar temperatur temper maka semakin kecil nilai kekerasan. Hal ini disebabkan oleh fasa yang semakin halus. Struktur mikro pada temperatur temper 500, 600 , dan $700^{\circ} \mathrm{C}$ menunjukkan fasa bainit yang semakin halus. Semakin besar temperatur temper maka semakin halus fasa yang terbentuk. Semakin halus fasa yang terbentuk maka semakin rendah kekerasan (semakin lunak).

Kehalusan fasa bainit dipengaruhi oleh perbandingan jumlah fasa ferit dan sementit. Perlakuan panas temper menyebabkan presipitasi sementit di antara ferit. Semakin tinggi temperatur temper maka semakin banyak presipitasi sementit. Hal tersebut menyebabkan jumlah sementit berkurang dan jumlah ferit bertambah.

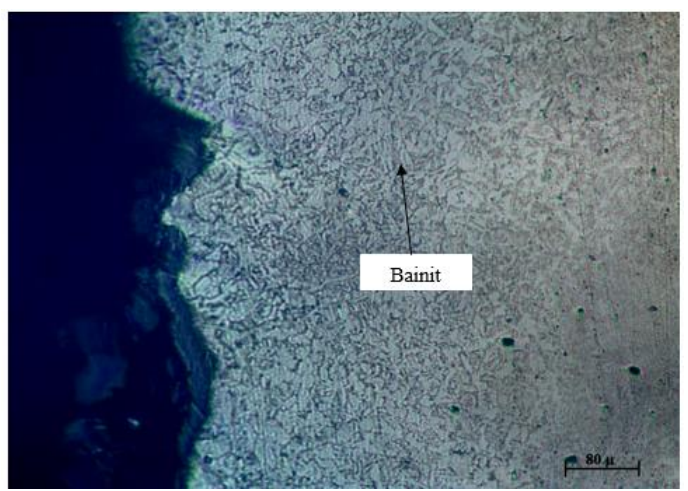

(a)

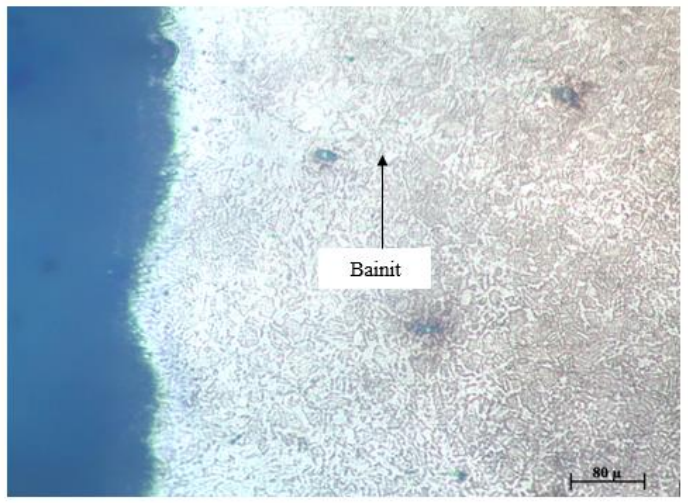

(b) 


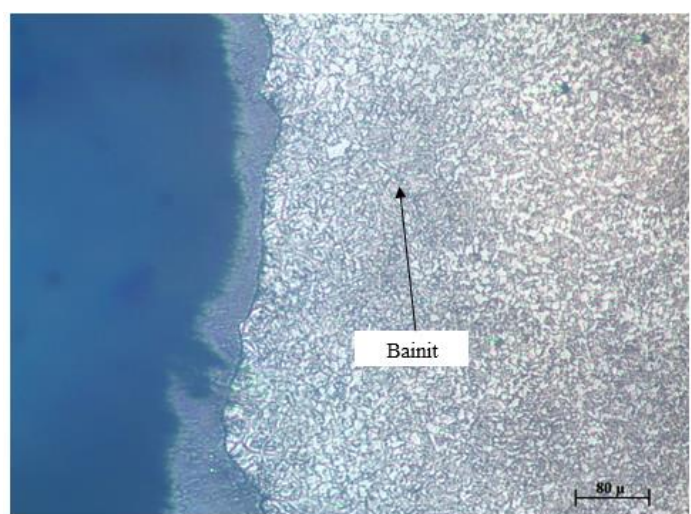

(c)

Gambar 10. Struktur mikro pada permukaan rim prototipe roda kereta api hasil perlakuan panas temper pada waktu tahan 1 jam (perbesaran 200X; daerah pinggir): (a) $500^{\circ} \mathrm{C}$; (b) $600^{\circ} \mathrm{C}$; (c) $700^{\circ} \mathrm{C}$

Struktur mikro prototipe roda kereta hasil perlakukan panas temper $500,600,700^{\circ} \mathrm{C}$ pada waktu tahan selama 3 jam dapat dilihat pada Gambar 11. Grafik kekerasan terhadap temperature temper pada waktu tahan 3 jam (Gambar 7) menunjukkan semakin tinggi temperatur temper maka semakin kecil kekerasan. Temperatur temper yang tinggi membentuk fasa bainit yang halus.

Nilai kekerasan dengan waktu tahan 1 jam lebih besar dibandingkan nilai kekerasan dengan waktu tahan 3 jam pada setiap temperatur temper yang sama. Struktur mikro pada waktu tahan 3 jam menunjukkan struktur mikro yang lebih halus dibandingkan pada struktur mikro dengan waktu tahan 3 jam. Hal tersebut menunjukkan bahwa semakin lama proses temper maka semakin halus fasa bainit yang terbentuk.

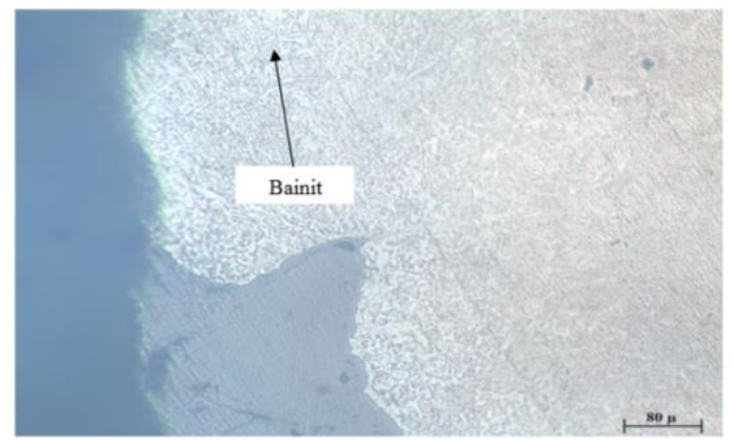

(a)

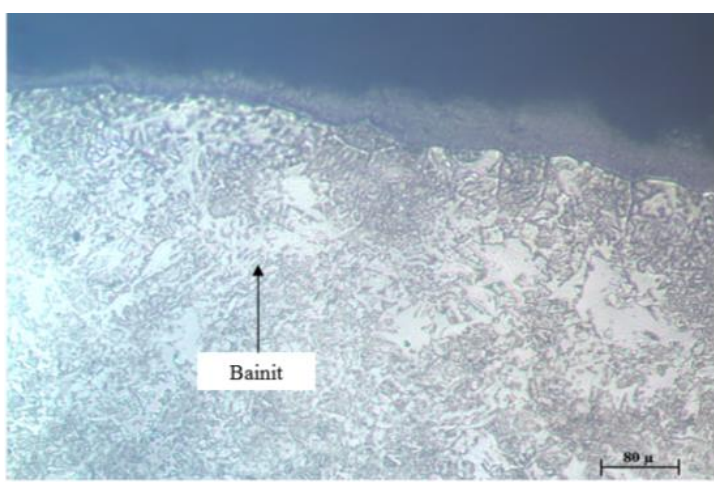

(b)

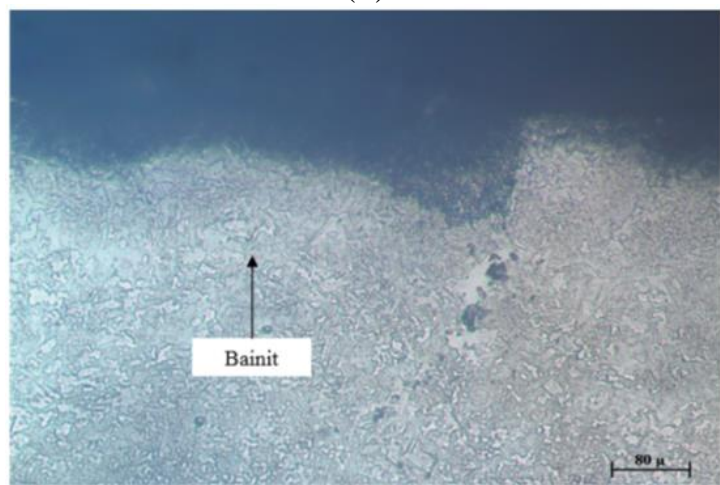

(c)

Gambar 11. Struktur mikro pada permukaan rim prototipe roda kereta api hasil perlakuan panas temper pada waktu tahan 3 jam (perbesaran 200X; daerah pinggir): (a) $500^{\circ} \mathrm{C}$; (b) $600^{\circ} \mathrm{C}$; (c) $700^{\circ} \mathrm{C}$

Keberadaan fasa ferit dalam fasa bainit memberikan pengaruh terhadap kekerasan prototipe roda kereta api hasil perlakuan panas temper. Semakin tinggi temperatur temper dan semakin lama waktu tahan maka semakin banyak terjadi presipitasi sementit sehingga menyebabkan fasa ferit semakin banyak (bertumbuh). Keberadaan fasa ferit yang semakin banyak dan fasa sementit yang semakin berkurang menyebabkan fasa bainit semakin halus. Fasa bainit yang halus memiliki kekerasan yang rendah.

Perlakuan panas temper akan menurunkan kekerasan namun akan meningkatkan ketangguhan. Penurunan kekerasan harus dalam batas yang masih diperbolehkan. Perlakuan panas temper pada temperatur $500^{\circ} \mathrm{C}$ dengan waktu tahan selama 1 jam menghasilkan kekerasan sebesar 311 HB (33 HRC). Nilai tersebut mendekati nilai standar kekerasan permukaan rim pada roda kereta berkisar 320 341 HB. 


\section{UCAPAN TERIMA KASIH}

Penulis mengucapkan terima kasih kepada Balai Besar Logam dan Mesin Kementerian Perindustrian yang telah mendukung pelaksanaan kegiatan penelitian ini.

\section{KESIMPULAN}

Perlakuan panas permukaan pengerasan induksi dengan temperatur $900^{\circ} \mathrm{C}$ dengan media pendinginan air mengubah struktur mikro permukaan rim prototipe roda kereta api dari perlit menjadi martensit dan bainit. Kekerasan permukaan didapatkan sebesar 381 HB. Kekerasan permukaan rim prototipe roda kereta api paling besar dihasilkan pada temperatur temper $500^{\circ} \mathrm{C}$ dengan waktu tahan selama 1 jam yaitu 311 HB. Semakin tinggi temperatur temper dan semakin lama waktu tahan menyebabkan kekerasan menurun karena semakin banyak fasa ferit yang tumbuh dan fasa sementit semakin berkurang. Fasa ferit yang semakin banyak mengakibatkan kekerasan menurun namun keuletan dan ketangguhan meningkat.

\section{DAFTAR PUSTAKA}

Aditiasari, Dana. 2015. "RI Baru Bisa Kuasai 40\% Komponen Kereta Api." Detik, November 25.

https://finance.detik.com/industri/d3080148/ri-baru-bisa-kuasai-40komponen-kereta-api.

Djumena, Erlangga, ed. 2018. "Menperin: Indonesia Pemain Besar Manufaktur Kereta." Kompas.com, January 18. https://ekonomi.kompas.com/read/2018/0 1/18/183100926/menperin-indonesiapemain-besar-manufaktur-kereta.

Doloksaribu, Martin, and Eva Afrilinda. 2014. "Peningkatan Kualitas Dodos Dengan Variasi Temperatur Austenisasi Dan Media Quenching.” Metal Indonesia 36 (1). Bandung, Indonesia: Balai Besar Logam dan Mesin: 1-7. http://jurnalmetal.or.id/jmi/article/view/20 12 . . 2016. "Pengaruh Krom Terhadap Sifat Mekanik Dan Struktur Mikro Pada Besi Cor Nodular 400." Metal Indonesia 38 (1). Bandung, Indonesia: Balai Besar Logam dan Mesin: 8-13. http://jurnalmetal.or.id/jmi/article/view/7.
Jiang, Ke, Ying-dong Qu, Jun-hua You, Rongde Li, Qing-chun Xiang, and Yu-xiong Zhou. 2016. "Influence of Cr Element on Impact Fracture Process of Ductile NiResistant Alloyed Iron at Low Temperature." China Foundry Research \& Development 13 (1): 42-46. doi:10.1007/s41230-016-5082-2.

Lu, Ding-shan, Zhong-yi Liu, Wei Li, Zhao Liao, Hui Tian, and Jian-zhong Xian. 2015. "Influence of Carbon Content on Wear Resistance and Wear Mechanism of $\mathrm{Mn} 13 \mathrm{Cr} 2$ and $\mathrm{Mn} 18 \mathrm{Cr} 2$ Cast Steels." China Foundry Research \& Development 12 (1). Guangzhou, China: Foundry Journal Agency: 39-47. http://ff.foundryworld.com/uploadfile/201 5021236264165.pdf.

Parzych, S. 2017. "The Effect of Heat Treatment on Microstructure and Mechanical Properties of Cast Bainitic Steel Used for Frogs in Railway Crossovers." Archives of Metallurgy and Materials 62 (4). Warszawska, Poland: de Gruyter: 2147-51. doi:10.1515/amm2017-0317.

Pratomo, Sri Bimo. 2013. "Pengembangan Pembuatan Roda Kereta Api Melalui Proses Pengecoran." Metal Indonesia 35 (1). Bandung, Indonesia: Balai Besar Logam dan Mesin: 14-20.

Pratomo, Sri Bimo, Hafid, and Eva Afrilinda. 2013. "Pengembangan Material Bainitic Cast Steel Untuk Komponen Tapak Rantai (Track Link) Kendaraan Tempur Tank Substitusi Impor." Jurnal Riset Industri 7 (3). Bandung, Indonesia: Kementerian Perindustrian: 173-82. http://ejournal.kemenperin.go.id/jri/article/ view/3216/pdf.

Pratomo, Sri Bimo, Husen Taufiq, Eva Afrilinda, and Martin Doloksaribu. 2016. "Pengembangan Material Tapak Roda Kereta Api Impor Dengan Penambahan Paduan Dan Perlakuan Panas Normalisasi Pendinginan Kipas." Jurnal Riset Industri 10 (2). Bandung, Indonesia: Kementerian Perindustrian: 83-91. http://ejournal.kemenperin.go.id/jri/article/ view/2720/2093.

PTKAI. 2009. Spesifikasi Teknik Roda Solid Kereta Dan Gerbong Golongan CC. Indonesia: PT Kereta Api (Persero). 